\title{
Haemangioendotheliosarcoma of the heart Diagnosis and treatment
}

\author{
P. BJERREGAARD AND U. BAANDRUP ${ }^{1}$
}

\begin{abstract}
From the University Department of Cardiology and the University Institute of Pathology, the Municipal Hospital, Aarhus, Denmark
\end{abstract}

SUMMARY A case of haemangioendotheliosarcoma of the right atrium in a 28-year-old man is reported. The presence of a continuous murmur to the right of the sternum as a clue to the diagnosis is pointed out, and the usefulness of cardiac catheterisation and angiography in making diagnosis emphasised. Irradiation therapy with cobalt- 60 had a palliative effect upon this malignant tumour.

Although only about 60 cases of primary cardiac haemangioendotheliosarcoma have been described, it is, together with rhabdomyosarcoma, the most frequent malignant primary tumour of the heart (Gröntoft and Hellquist, 1977). The clinical picture in the published cases has tended to uniformity, but without specific clues to the diagnosis-a malignant primary cardiac tumour was suspected during life in only 13 of these patients and in only 8 was the diagnosis of haemangioendotheliosarcoma established before death. Three of these received irradiation therapy, with varying results. In the remaining patients the average survival time from the onset of symptoms was approximately 6 months.

Our patient is of special interest as clinical signs and findings at cardiac catheterisation enabled a presumptive diagnosis of a malignant angiomatous tumour in the right atrium to be made. This diagnosis was subsequently confirmed at operation.

The effect of irradiation and chemotherapy was evaluated at an advanced stage of the disease.

\section{Case report}

A 28-year-old man was in good health until November 1975, when he developed fever, cough, and a sore throat. $\mathrm{He}$ was given penicillin without improvement.

In February 1976, he was seen by a cardiologist after a chest $x$-ray film had shown slight cardiac enlargement. A friction rub was heard over the heart and because of a raised antistreptolysin $O$ 'Present address: Department of Histopathology, National Heart Hospital, London. titre, rheumatic fever was suspected. Treatment with phenoxillin was started but he failed to improve, complaining of fatigue and dyspnoea.

In October 1976, he was admitted to our department after an episode of haemoptysis. On examination there was no jugular venous congestion. The only remarkable finding was a continuous murmur (grade 2-3/6) maximal in the fifth and sixth intercostal spaces approximately $4 \mathrm{~cm}$ to the right of the sternum. The murmur was unaffected by respiration and body position, and it was inaudible in the classical sites of auscultation. There was a split second sound with an accentuated pulmonary component. The electrocardiogram was normal and remained so thereafter. The chest $x$-ray showed that the heart was moderately enlarged, with a bulging and slightly irregular right cardiac border. In both lung fields small scattered infiltrates were seen. Urinanalysis, routine haematology and biochemistry, ESR, liver function studies, serum protein electrophoresis, and various serological tests for viral and fungal infection were all normal. There were no lupus erythematosus cells and cultures for tuberculosis from the sputum and gastric aspirate were negative. Bronchoscopy revealed blood in the bronchial tree, but no tumour tissue was seen in biopsy material.

Right-sided cardiac catheterisation (Table) disclosed normal pressures and cardiac index, but the oxygen saturation showed a small but consistent step-up between the venae cavae and the pulmonary artery with the main increase at right ventricular level, suggesting a left to right shunt. Catheter manoeuvrability suggested an abnormality in the 
Table Cardiac catheterisation

\begin{tabular}{lllll}
\hline Site & $\begin{array}{c}\text { Pressure } \\
(\mathrm{m} m . \mathrm{Hg})\end{array}$ & Oxygen saturation $\left(\% \mathrm{O}_{2}\right)$ \\
\hline Superior vena cava & & 64 & 63 & 60 \\
Inferior vena cava & $11 / 5$ & 60 & 59 & \\
Right atrium & $11 / 10$ & 63 & 66 & 66 \\
Right ventricle & $26 / 10$ & 73 & 73 & 71 \\
Pulmonary artery & $26 / 12$ & 100 & & 69 \\
Pulmonary wedge & 12 & & & \\
& & $2.61 / \mathrm{min}$ per $\mathrm{m}^{2}$ & & \\
\hline
\end{tabular}

lower part of the right atrium and a biplane angiocardiogram confirmed the presence of a tumour bulging into its cavity and compressing the superior vena cava (Fig. 1).

The continuous murmur, the left-to-right shunt, and the filling defect in the right atrium suggested an angiomatous tumour in the right atrium also probably infiltrating the right ventricle.

In December 1976, the heart was exposed through a median thoracotomy and the diagnosis of a haemangioendotheliosarcoma confirmed by biopsy. The tumour was deemed inoperable as several metastases were seen in the left lung. Postoperatively the patient was very dyspnoeic and needed continuous oxygen therapy. He was irradiated with cobalt 60 to a total of $3000 \mathrm{rad}$, and then given chemotherapy (lomustine, doxorubicin, vinblastine, and prednisone). Over the next 2 months he improved suffic- iently to be discharged but in April 1977, bronchopneumonia developed and he died 17 months after the initial symptoms.

\section{PATHOLOGY}

\section{Necropsy, gross}

The pericardium was adherent to the surroundings and contained no fluid.

The heart weighed $630 \mathrm{~g}(1.3 \%$ of the total body weight) and measured $10 \times 11 \mathrm{~cm}$. The right atrium was enlarged and had several dark tumour nodules on the surface, the largest being $1.2 \mathrm{~cm}$ in diameter (Fig. 2a). The wall of the right atrium was greatly thickened and firm (Fig. 2b), the colour varying from grey-yellow to dark red. The tumour occupied two-thirds of the right atrial wall and continued from the orifice of the superior vena cava into the epicardial tissue surrounding the right coronary artery.

Numerous metastases were found in both lungs and two in the liver; they were all red and full of blood.

\section{Microscopy}

All sections were stained by $\mathrm{H}+\mathrm{E}$, elastic van Gieson, PTAH, reticulin stain, and Masson's trichrome method. Sections from the right atrial wall and the upper part of the anterior wall of the right
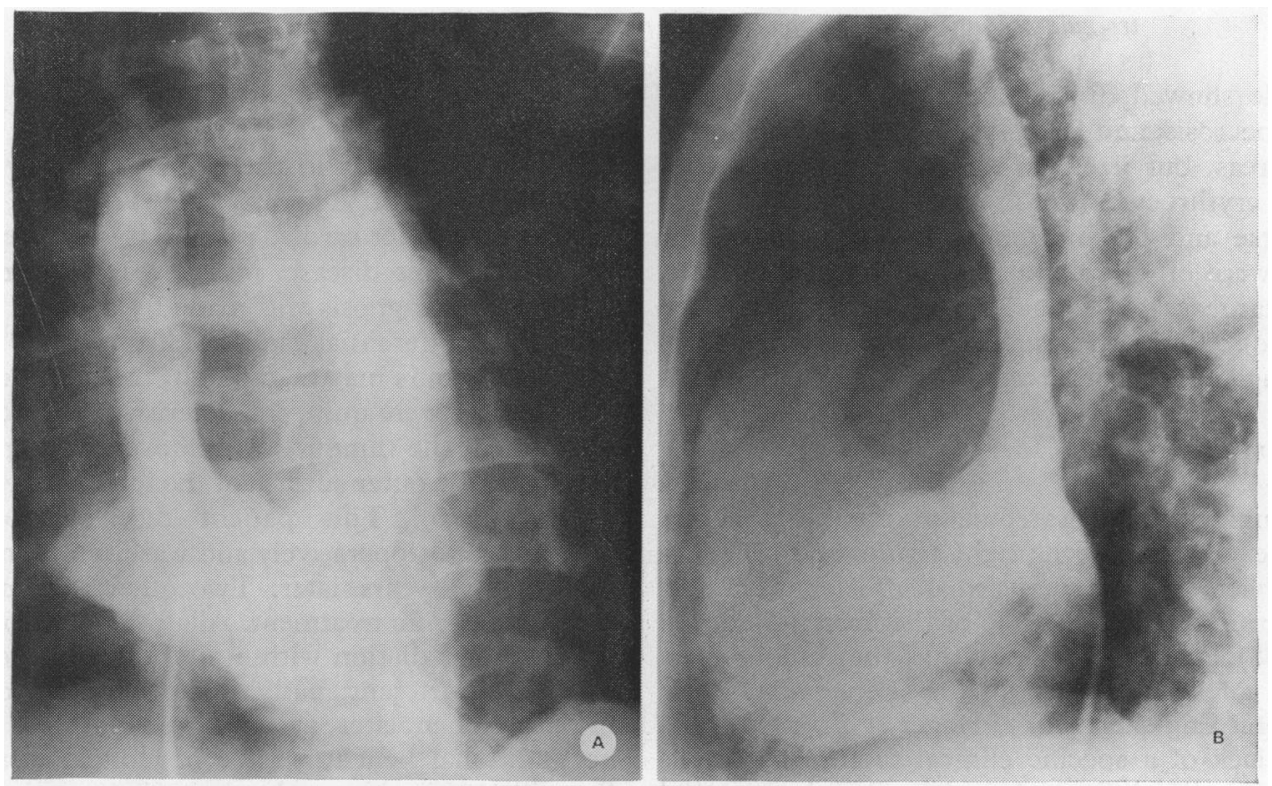

Fig. 1 Biplane angiocardiography. (A) Frontal projection. (B) Lateral projection. Films selected from serial studies made after injection in the right atrium. There is opacification of the superior vena cava, the right atrium, the right ventricle, and the pulmonary artery. The right atrium is seen to be the site of a large irregular filling defect. 


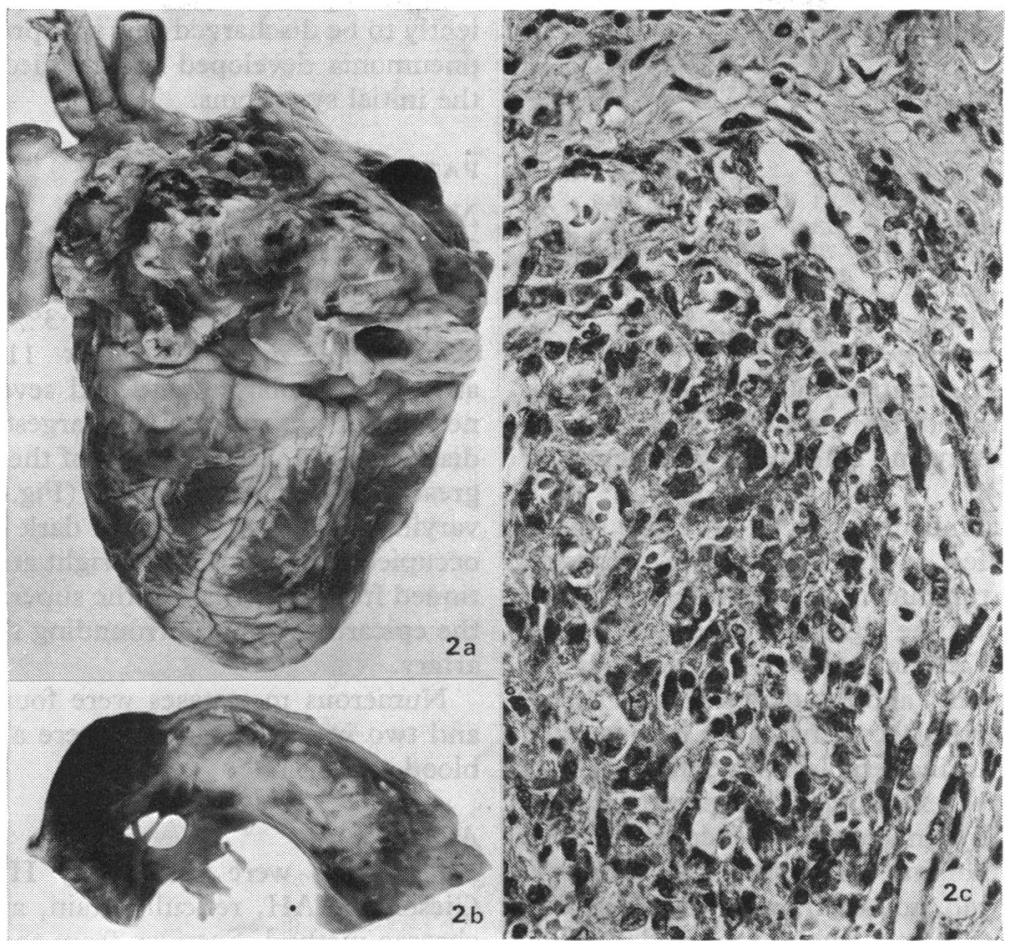

Fig. 2 (a) Posterior aspect of the heart. Large tumour nodules are seen at the top right. (b) Section from the right atrium through the largest tumour nodule (real size). (c) Section from the tumour tissue. Erythrocytes are seen in several of the irregular channels lined by malignantly transformed endothelium. $(H+E . \times 330$.

ventricle showed diffuse tumour growth, haemorrhage, necrosis, and fibrosis. The tissue was solid in some areas, but irregular clefts and channels containing erythrocytes were seen in many parts, lined by coarse and pleomorphic endothelial cells. The nuclei were often spindle shaped, hyperchromatic, and enlarged; 1 to 2 nucleoli were frequently seen (Fig. 2c). The appearances were consistent with haemangioendotheliosarcoma.

\section{Discussion}

Haemangioendotheliosarcoma of the heart occurs almost exclusively in the right atrium and produces either haemorrhagic pericardial effusion or inflow obstruction of the right side of the heart (Glancy et al., 1968). In only 3 patients has the tumour been located solely in the left atrium (Penneman, 1908; Gross and Englehart, 1937; Hager et al., 1970).

The lack of a specific clinical picture has made diagnosis in life difficult. In at least 7 of the reported patients tuberculosis was suspected (Kauder and Müller, 1968; Freeland et al., 1971; Tse and Frank, 1971 ; Patt et al., 1974).
Lange and Christiansen (1947) arrived at the diagnosis by exclusion. Cheng and Sutton (1955) showed the tumour in the right atrium by angiocardiography, and Thompson et al. (1977) carried out the only other cardiac catheterisation previously reported in this disease, in a 9-year-old girl. In 4 patients the diagnosis was made by tumour biopsy. While the differential diagnosis from other mesenchymal tumours may be difficult, the morphological appearances were quite characteristic in our case. In one patient the tumour was removed during operation from the outer surface of the left atrium (Hager et al., 1970). This patient received cobalt-60 irradiation postoperatively and was asymptomatic at follow-up 3 years later. Two other patients have received specific treatment. Allaire et al. (1964) used cobalt-60 irradiation with a total of 5630 rad given over the heart, and palliation was obtained for 2 months. When, later, cyclophosphamide was added, no additional benefit was seen. Hollingsworth and Sturgill (1969) also used cobalt-60 (a total of 5400 rad) combined with vincristine and cyclophosphamide in a patient in whom the neoplasm was located at the base of the heart and over the right 
atrium, but with no tumour mass within the atrium. The patient tolerated the treatment well and was free of symptoms 10 months later.

In our patient the tumour, though classically located in the right atrium, did not, atypically, cause either cardiac tamponade or right-sided inflow obstruction. The continuous murmur over the tumour was not heard before admission and has not been described in any other of the published cases. Such a murmur may have been missed, since it was located well away from the usual sites of auscultation. The increase in oxygen saturation between the venae cavae and the pulmonary artery suggests a direct communication between the highly vascularised tumour and the right-sided chambers. Angiocardiography showed no evidence of septal defects, but indicated an area of dense arterialisation in the tumour suspected area when the contrast material was passing the aorta.

Irradiation and chemotherapy were started late in the course of the disease, but palliation was obtained for only 2 months, owing mainly to the direct cobalt -60 irradiation of the heart and the metastases in the left lung.

Our experience, therefore, confirms the impression that irradiation therapy has at least a palliative effect in the treatment of haemangioendotheliosarcoma of the heart.

\section{References}

Allaire, F. J., Grimm, C. A., Taylor, L. M., and Pfaff, J. P., jun (1964). Primary haemangioendothelioma of the heart: report of a case treated with irradiation and cyclophosphamide. Rocky Mountain Medical fournal, 61, 34-37.

Cheng, T. O., and Sutton, D. C. (1955). Primary hemangioendotheliosarcoma of the heart diagnosed by angiocardio- graphy; review of the literature and report of a case. Circulation, 11, 456-461.

Freeland, J. P., Sy, B. G., Ahluwalia, M. S., and Dunea, G. (1971). Hemangiosarcoma of the heart. Chest, 60, 222-224.

Glancy, D. L., Morales, J. B., jun, and Roberts, W. C. (1968). Angiosarcoma of the heart. American fournal of Cardiology, 21, 413-419.

Gross, P., and Englehart, C. E. (1937). Primary hemangioendothelioma of the heart: report of a case. American Fournal of Cancer, 30, 102-107.

Gröntoft, O., and Hellquist, H. (1977). Cardiac haemangio-

endotheliosarcoma: review of the literature and report of a case. Acta Pathologica et Microbiologica Scandinavica, Sect. A, 85A, 33-41.

Hager, W., Kremer, K., and Müller, W. (1970). Angiosarkom des Herzens. Deutsche medizinische Wochenschrift, 95, 680-684.

Hollingsworth, J. H., and Sturgill, B. C. (1969). Treatment of primary angiosarcoma of the heart. American Heart fournal, 78, 254-258.

Kauder, H., and Müller, S. (1968). Angioblastisches Sarkom des Herzens. Thoraxchirurgie, 16, 214-220.

Lange, H. F., and Christiansen, T. (1947). Hemopericardium -angiosarcoma cordis: a case of primary heart tumour diagnosed intra vitam. Acta Medica Scandinavica, 127, 107-115.

Patt, Y. Z., Halkin, H., and Jaffe, R. (1974). Primary cardiac angiosarcoma. Israel fournal of Medical Sciences, 10, 525-528.

Penneman, G. (1908). Note sur un cas d'hémangioendothéliome du coeur. Annales et Bulletin de la Société Royale de Médecine de Gand, 88, 57-66.

Thompson, D. S., Westaby, S., and Lincoln, J. C. R. (1977). Ventricular haemangioendothelioma diagnosed in life. British Heart fournal, 39, 462-465.

Tse, R. L., and Frank, M. N. (1971). Angiosarcoma of the heart. First reported case in an adolescent. Angiology, 22, 147-152.

Requests for reprints to Dr P. Bjerregaard, Cardiologisk Afdeling, Kommunehospitalet, 8000 Aarhus C, Denmark. 